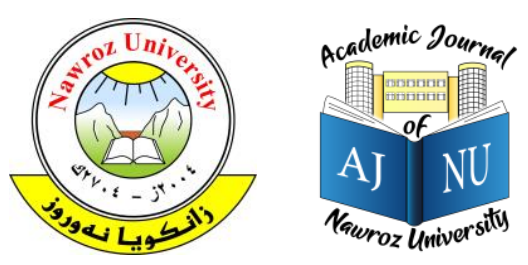

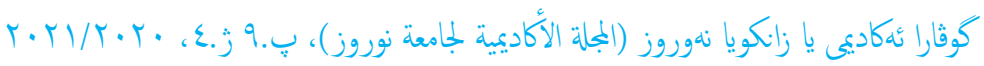

حقوق الطبع والنشر (2017. هذه مقالة الوصول اليها مفتوح موزعة تحت رخصة

e-ISSN: 2520-789X ،CC BY-NC-ND 4. 0. - المشاع الايداعي النسبي

https://doi.org/10.25007/ajnu.v9n4a1102

\title{
الجودة المدركة لخدمات الموقع الإلكتروني وأثرها في تعزيز التميز الأكاديمي دراسة استطلاعية لآراء عينة من التدريسيين في جامعة دهوك
}

د. سعد فاضل عباس المحمود، قسم إدارة الأعال، جامعة دهوك، كردستان العراق

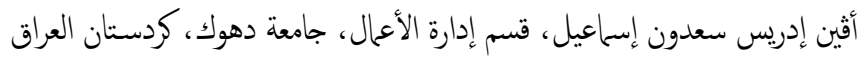

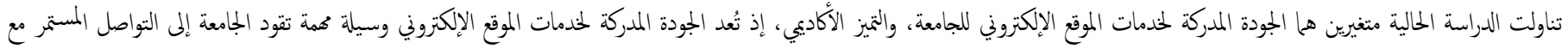

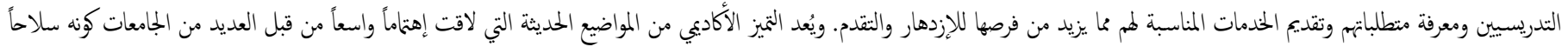

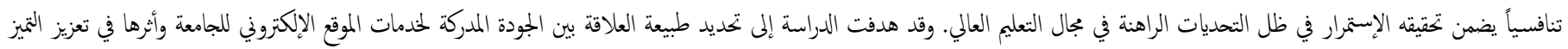

الآكاديمي.

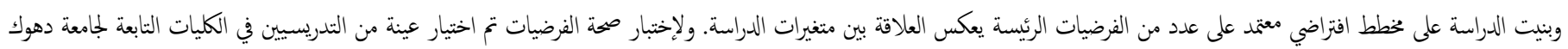

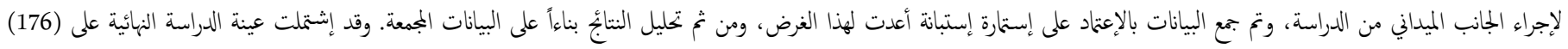

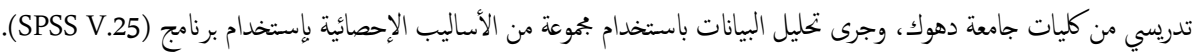

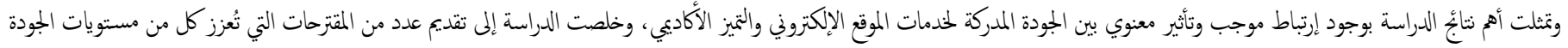

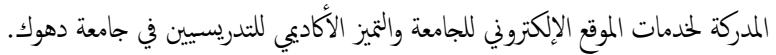
الكلمات المفتاحية: الجودة الخدمة الإلكترونة، الموقع الإلكتروني، الجودة المدركة، التميز الأكاديي.

1. مقدمة

وأصبح التميز الأكاديي من جانب آخر هاجساً ومطلباًة قوياً تسعى إليه الجامعات كافة وذلك بإعتباره وسيلة لتحقيق ميزة تنافسية تعزز من مكانتها ضمن التصنيفات المحلية والعلمية، إذ أن الإستعانة بالتكنولوجيا الحديثة وشبكة الانتزنت ساهت في تعزيز التميز الأكاديي وذلك من خلال إعتاد أحدث التقنيات التي تسهل ذلك ومنها إنشاء مواقع إلكترونية ذات جودة عالية تدع الفئات الأكاديمة في سعها لتحقيق التمبز.

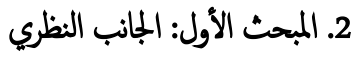
1.2 الجودة المدركة لحدمات الموقع الإلكتروني 1.1.2 مفهوم الجودة المدركة لخدمات الموقع الإلكتروني تقوم المنظلات بإنشاء المواقع الإلكترونية لأغراض كثيرة منها التسويق أو التعامل مع المنتجات أو تقديم محتوى للجمهور المستهدف، وبالتالي تعد المواقع الإلكترونية بوابات لمعلومات المنظلات وسلعها وخدماتها، على هذا النحو، ومن المهم أن يكون
ساعدت تكنولوجيا المعلومات والإتصالات بشكل عام وشبكة الأنترنت بشكل خاص على تغيير الطريقة التي تقدم بها المنظات الخدمات لزبائها أو مستخدميها وذلك بإختصار المسافة بينها وبينه وعن طريق خدماتها التفاعلية عبر مواقعها الإلكترونية والتي تمكن المستفيدين من الوصول إلى المعلومات المطلوبة والتفاعل معها عبر أبهزة الحاسوب. ويُعد قطاع التعليم واحد من أهم القطاعات التي تعتمد الإنتزنت بشكل مكثف حيث غيرت الجامعات الطريقة التي تُدار بها عملياتها الأساسية والداعمة للأعمال من خلال السحاح للمستفيدين من أداء مهامم الخختلفة عن بُعد والتي كانت تؤدى بالطريقة التقليدية في السابق، كممليات الندريس، القبول، التسجيل، وتقديم الإستشارات وغيرها. كما غيرت شبكة الإنتزنت عملية التعلم من الطريقة التقليدية (وجهاً لوجه) إلى التعلم عن بُعد أو التعلم الإلكتروني، لذلك أصبحت إدارات المنظلات التعليمية والأكاديمة تواجه تحدياً كبيراً في كيفية صياغة وتقديم خدمة ذات جودة عالية تراعي متطلبات المستفيدين والإستجابة لها وبالتالي تحقق الرضا للدهم. 


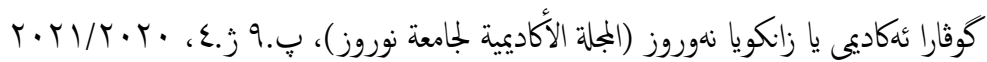

فيرتبط عادة بتعامل محدد (Vieira et al., 2012: 22). وقد عرف (طواهير والهواري، 2012: 99) جودة الخدمة الإلكترونية بأنها درجة تسهيل موقع إلكتروني لعمليات التخزين، الشراء والتسليم للسلع أو المذمات، فهذا المفهوم كما هو ملاحظ يجتوي على بعدين البعد النفي والمتمثل في درجة التسهيل والبعد العاطفي المتمثل في بمحل العواطف والأحاسيس التي يشعرها مستخدم الانتزنت عند زيارته للمواقع.

\subsection{2 أبعاد الجودة المدركة لخدمات الموقع الإلكتروني}

تناولت الدراسة بموعة من الأبعاد لتحديد مضامين الجودة المدركة لخدمات الموقع

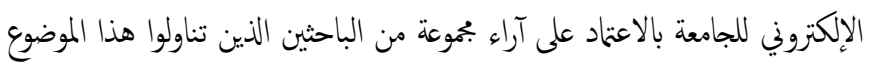

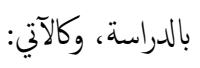

1.2.1.2 الإستجابة (سرعة الوصول) عُرفت الإستجابة على أنها القدرة على التعامل الفعال مع المثاكل والعوائد المتحققة في الموقع الإلكتروني (Connolly et al.,2010: 651) وعرفت أيضاً على أنها الميل والرغبة لمقدمي الخدمات لمساعدة الزبائن وتلبية إحتياجتهم، والرد على استفساراتهم وحل مشاكلهم في أسرع وقت مككن بالاضافة إلى امتلاك العاملين الخبرة الكافية في التعامل مع التكنولوجيا المستخدمة بالمنظمة (Al- et al.,2018:139) Zoub إعطاء اهتمام سريع لطلب المستفيد والقدرة على تحديد تصوره وإدراكه لجودة تلك الخدمة (Muhammed and Yusuf, 2016: 145). ويشير هذا البُعد بشكل عام إلى قدرة موظفي المنظلات أو مقدي الخدمة على تزويد الزبائن أو المستفيدين بخدمة سريعة(Raluca et al.,2018: 56)، ويعرفها (الرواحنة، 2012 : 29) بأنها الاستعداد لمساعدة المستفيدين وتقديم الخدمات بالسرعة المطلوبة، وتعبر الإستجابة أيضاً عن الزمن المستغرق للحصول على رد عند القيام بإجراء معين على الموقع (24: (Hidayanto et al.,2015: 283) (الكساسبة، 2014 (ايرى كل من و(حسين، 2011: 27) أن الإستجابة يقصد بها تقديم المساعدة وتزويد المستفيدين بالخدمة بشكل سريع حيث تقاس بسرعة الرد على أسئلة الستفيدين وحل مشاكلهم على الفور والقدرة على حل المشكلات بشكل آلي مثل الشكوى عن طريق الانتزنت والضمانات على الاتنزنت.
لدى المنظات مواقع إلكترونية ترتقي لمستوى توقعات الجمهور المستهدف لتحقيق الأهداف المنشودة (Sife and Msoffe, 2013:1 ). ويعرف الموقع الإلكتروني بأنه جمحوعة من الصفحات والنصوص والصور والمقاطع الفيديوية المتزابطة وفق هيكل متناسب ومتفاعل بهدف إلى عرض ووصف المعلومات والبيانات عن جهة أو منظمة ما ، بجيث يكون الوصول إليه غير محدد بزمان ولا مكان وله عنوان فريد محدد يميزه عن بقية المواقع على شبكة الانتزنت (حسين، 2010: 38) ويعرف الموقع أيضاً بأنه وسيلة معلومات وتكنولوجيا إتصالات والتي تُستخدم لعرض محتوى المعلومات بريقة سريعة ورخيصة وقاباة للتطوير (Napitupulu,2017: 792$)$ مصطلح الجودة المدركة للخدمة إلى المفهوم الذي يقيس الاختلاف ما بين توقعات متلقي الخدمة ومدركاته الفعلية نحو الخدمة (Porral et al., 2013: مجموعة من السمات التي تسهم في الإدراك حول جودة المنتج (سلعة أو خدمة) على المستوى الذي يحدده المستهلك (Rolland and Desmet, 2007:4). وفي ذات السياق فإن الجودة المدركة تعمد على ما يتشكل من صور ذهنية لدى المستفيد حول أداء الخدمة التي قاموا بإستخداهما بالفعل وتقييهم لها بناءاً على النتائج أو الفائدة المحصلة منها (الدهيات، 2011: 20)، وهي تعبر عن كل الإنطباعات والتعابير الحسية التي تجذب إنتباه المستخدم والتي يقوم بتفسيرها كوعود بالجودة مما يولد لديه الثقة والشعور بالرضا (Othmani and Bouslama, 2015).وقد استخدم مفهوم الجودة المدركة بكثرة في الادبيات المتعلقة بالتسويق من خلال قياس سلوك المستهاك حول كيفية تحديد الفجوة بين توقعات الزبائن وبين إدراكهم لجودة الخدمة الفعلية المقدمة (Muhammed and Yusuf, 2016: 144) أو إلى أي مدى يكن للموق الإلكتروني أن يسهل من التسوق ، الشراء وعملية التسليم بكفاءة وفاعلية (Parasuraman et al., 2005: ويرى (650: Connolly et al.,2010) أن توقعات الزبائن هي المفتاح لقياس جودة الخدمة فعندما تكون توقعانهم أعلى من الأداء الفعلي تكون جودة الخدمة منخفضة، أما اذا كانت توقعاتهم ادنى وكان الأداء الفعلي أعلى هذا يعني أن الجودة عالية، لذلك فإن الجودة المدركة للخدمة تتشابه مع رضا الزبون بالبنية ولكنها تبقى مستقلة عنه ولقد عرفت الجودة المدركة على أنها موقف أو حكم عام مرتبط بدرجة اتقان الحدمة، أما رضا الزبون 


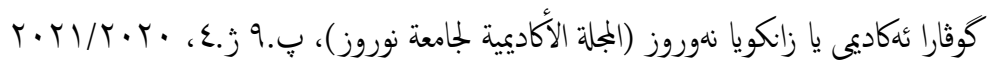

Parasuraman et al., ) ،(Alkhouli, 2018: 5 ) ، (al.,2010: 651

7 :2005). وينطوي الأمان على حاية المعلومات الشخصية وحاية المستخدمين

من الاختاق و الاطلاع على المعلومات الشخصية (الكساسبة، 2014: 24) كما

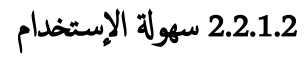

يعبر عنصر الأمان في بعض أنواع الخدمات عن سلامة وأمن المتعاملين معها

كالخدمات الكهربائية مثلاً (Muhammed and Yusuf, 2016:145).

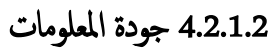

قياس هذا البعد من حيث الدقة والحداثة في المعلومة بحيث تكون المعلومات على الموقع دقيقة، وأن تكون مصادر المعلومات على الموقع موثقة وحديثة وتشير بوضوح إلى عدد مرات التحديث للمستخدم. أيضاً يقاس هذا البعد بكفأية وشمول المعلومات أي حصول المستخدم على معلومات دقيقة وكاملة وواضحة وذات مصداقية عند زيارة الموقع ( عبدة، 2012: 31). ويتضمن هذا البعد الخصائص التي يجب أن تتوفر في مخرجات نظام المملومات على شكل تقارير أو التي يتم عرضها على الموقع الإلكتروني بجيث تكون المعلومات ذات جودة من حيث الدقة والحداثة والترابط وسهولة الفهم من قبل المستخدم (Napitupulu,2017: 793 (إذ يجب ان تتوفر أربعة أبعاد في المعلومة حتى تكون ذات قيمة وهي الترابط (وتعني أن يتم تقديم معلومات ذات صلة بالمشكلة المراد حلها)، الدقة ، والتوقيت (أي تتوفر في الوقت المناسب)، والتكمل أي ان تقدم صورة كامة عن المشكلة التي يريد المستخدم حلها (الرواحنة، 2012: 25-26). وفيا يخص المنظلات الأكديمية (الجامعات) بيجدر بمواقعها الإلكترونية أن تتضمن معلومات متعلقة بالصفحة الرسمية للجامعة وللكليات التابعة لها والتسهيلات التي تقدها الجامعة وإنجازات الجامعة وعن الحياة في الحرم الجامعي، وآليات تسجيل وقبول الطلبة الجدد، وأجور الدراسة وغيرها

.(Hidayanto et al.,2015: 283-284) 2.2

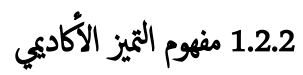
المقصود بالتميز الأكاديمي هو تلك الخاصية التي تعبر عن قدرات أعضاء هيئة التدريس والموظفين والإداريين في تنفيذ أهداف الجامعة التي يجب أن تتوافق مع
يشير مفهوم سهولة الإستخدام إلى مدى قابلية الثفاعل بالنسبة للمتعاملين مع الموقع الإلكتروني وذلك بسهولة التنقل وتنظيم الموقع بشكل جيد، ويشير أيضاً إلى سهولة وسرعة إنجاز المستخدمين لمهاهم (الكساسبة، 2014: 23). ويقيس هذا البُعد سهولة تصفح الموقع من قبل المستخدم ومدى ملائمة طريقة تصميم الموق لطبيعة الخدمات المقدمة من خلاله بالتركيز عل الجوانب التقنية (الرواحنة، 2012: 26). كما أن بُعد سهولة الإستخدام في الجمال الأكاديمي يشير إلى إستخدام موقع الجامعة فيما يتعلق بالدراسة والبحث عن المعلومات واختيارها وتوفرها بسهولة (عبدة، 2012 :31)، وسهولة تصفح الموقع وتقديم الطلبات وإكتال المعاملات والوصول للتعليمات في الوقت المناسب (عودة، 2012 : 30). كما يتطلب هذا البُعد أن يمنلك الموقع نظاماً يسهل من عملية الانتقال من صفحة إلى أخرى ويكون سهل التعلم. يقوم هذا البُعد بدراسة آلية عمل الخدمة الإلكترونية ومدى سهولة إستخدامها بالنسبة للمستخدمين ومدى وضوح الأوامر والخطوات لإنجاز أي عملية، ويجب أن تصمم الحدمات الإلكترونية التي تقدها المواقع على أن تكون سهلة الإستخدام من قبل كافة الفئات العمرية وتراعي جميع المستويات الثقافية والعلمية للمستخدمين مما يضمن إستخدام امثل لخدمة الموقع الإلكتروني على نطاق أوسع فالخدمات الإلكترونية المعقدة هي أقل إستخدام لانها تتطلب بحداً كيراً واهتماً من جانب

المستخدم( Hidayanto et al.,2015: 283).

3.2.1.2 الخصوصية (الأمان والسرية)

يُقيم هذا البُعد درجة حاية الموقع الإلكتروني ومحافظته على المعلومات المتعلقة بالزبائن من الاختراق ومدى شعور الزبائن بالأمان على معلوماتهم الخاصة اثناء التعامل مع الموقع الإلكتروني ومدى قدرة مزود الخدمة على توفير الثقة لدى المستفيدين من خلال القدرة على تقديم الخدمة بإسلوب لائق ومناسب لهم (فهو يسمح بإحداث نوع من التنسيق والتفاعل (الرواحنة، 2012: 27-28) ، أي Conolly et ) الدرجة التي يكون فهيا الموقع آمن ويحمي معلومات الزبون 


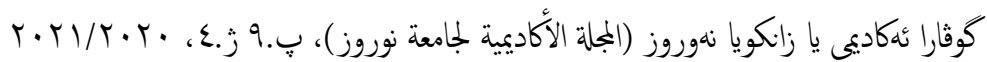

التزام الجامعة بتقديم أفضل المارسات في التعليم والتعلم والعلوم والإبداع الثميز في الإدارة

إن التميز الإداري في المنظمة يتحقق من خلال النمو والتطوير المستمر في جميع جوانها التنظيمة، وتنسيق الجهود والأنشطة والأعال من أجل ذلك، مما يسهم في تحتيقها لأهدافها، حيث يوجد الكثير من المنظات في الوقت الحالي تبحث عن التميز ، ولكن القليل منها هو الذي يتمكن من تحقيق هذا الهدف. فالتميز في الإدارة يتطلب تميزاً في التنظيم وهو الحالة الصحية التي ينبني أن تكون عليها المنظلات التي لا تتحقق بمض الصدفة بل بمجمل تميز القادة وبجمود وتميز العاملين، وذلك تحت تأثير ثقافة تنظمية تدع هذا التميز (الشهراني، 2017: 36-37)، من جانب اخر فإن للقيادة العليا تأثير مباثر على التميز وذلك عن طريق تنمية قدرات الأفراد وتشجيعها لمم بالتوجه نحو التميز وذلك من خلال تميزها بالمهارة القيادية وعلاقات العمل الفعالة، وهناك بموعة من النشاطات التي يجب أن يقوم بها القادة لتشجيع ظهور التميز في المنظمة فنظام اللامركزية في العمل داخل المنظمة يسهل انسياب المعلومات والافكار الابنكارية بين العاملين والقيادة العليا مباشرة دون حواجز بيروقراطية كذلك فإن القدرة الابتكارية لدى الأفراد تتأثز بنمط القيادة الديمقاطية. فالقائد المتميز الذي يستطيع رؤية الكثير من المشكلات في الموقف الواحد يعي الاخطاء ونواحي القصور ويشعر بالمشكلات ويدركها في المواقف كافة ويتداركها بالتالي تزداد درجة التميز لديه، كما أن المنظمة بأبسط معانيها عبارة عن تجمعات بشرية هادفة لذلك فإن البنية الاساسية لأي منظمة هي العنصر البشري وبالتالي يُعد احد المحاور الأساسية للتميز وذلك لكونه يمثل الجهة المسؤولة عن اتخاذ القرار وعن التجديد والابنكار وهو وسيط التعلم في المنظمة وبالرغز من الأساليب الكمية الحديثة في مجال عملية اتخاذ القرارات التنظيمية الا ان العنصر البشري يبقى العنصر الحاكم في عملية اتخاذ القرارات (البحيصي، 2014: 33-35).

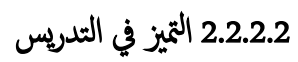
يعبر التميز في التدريس عن الدرجة العالية أو المستوى العالي من بلوغ الأهداف التي تلبي المعايير المعتمدة وتوفر أفضل نتيجة مطلوبة وفق جميع الشروط الموضوعة (Berghout, 2011: 151)، وتُعد عملية تقييم الجودة في التدريس قضية قديمة في التعليم العالي إذ أن التميز في التدريس مصطلح متنازع عليه فهناك وبجات نظر مختلفة
.(Varlamova, 2016: 1) ويتطلب تحقيق التميز الأكاديمي من قبل أي جامعة بناء أموذجج يتكون من ثلاثة عناصر أساسية هي (الموهبة، الموارد/ التمويل الكلفي، والحوكة/ الحكم الرشيد)، فالموهبة عامل نجاح رئيس في بناء جامعة بحثية فهي تمثل القدرة على جذب وتجنيد والاحتفاظ بالأكاديمين الرائدين وتوظيف أعضاء هيئة تدريس مؤهلين تأهيلاً عالياً وزيادة نسبة الدورات التدريبة، كما أن بناء فريق أكاديمي قوي لا يقتصر فقط على جذب ذوي الحبرة بل أيضا على التوصل إلى توازن جيد بين الأكاديمين في ذروة حياتهم المهنية والباحثين، بالاضافة إلى التزكيز على أهمية طلاب الدراسات العليا كحرك رئس للنجاح. أما الموارد فهي تعبر عن إحتياج الجامعات البحثية إلى موارد جيدة للتقدم السريع فلا غنى عن تمويل وفير على المدى الطويل ليس فقط من أجل إعداد البنية التحتية المادية المناسبة ولكن أيضاً لجذب والإحتفاظ بالأكادييين رفيعي المستوى. والعنصر الثالث هو الحوكمة التي تعبر عن الإطار التنظيمي المناسب، قيادة قوية وملهمة، وإدارة كفوةة فالرواتب الجيدة ليست كافية لجذب وتحفيز الأكاديمين ذوي الأداء العالي، حيث أن أعضاء هيئة التدريس يجب أن يشعروا أنهم جزء من (Altbach and Salmi, مشروع عم لضمان إلتزامم الكمل نحو بناء تميز المنظمة 2011:326-333).

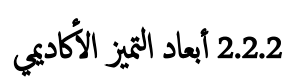
إن المنظلات المتميزة هي التي تحرص على ترجمة رؤيتها ورسالتها وأهدافها إلى واقع ملموس، من أجل تحقيق طموحاتها، والتي تسعى من خلالها إلى دع وتشجيع التميز والإبداع في مختلف أننطة ومجالات عملها، حيث أصبح التميز صفة حتمية فرضتها العديد من الظروف والقوى الخارجية ففي ظل التغيرات الحاصلة لم تعد المنظلات مطالبة فقط بتحقيق الأداء، وإنما التميز فيه كضرورة من أجل البقاء والاستمرارية والتنافس (البحيصي، 2014: 27) .وعليه نرى الباحثة وبناءاً على ما تبين من المراجعة النظرية للتميز الأكاديمي انه يككن دراسة التميز الأكاديمي وفقاً للأبعاد الآتية والتي تناولتها عدد من الدراسات ذات الصلة منها دراسة (Kauppila, 2016)، ودراسة ( Brusoni et al.,2014) وكلآتي: 


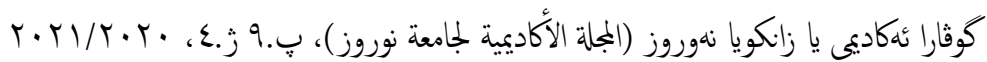

بالاضافة إلى براءات الاختراع. وبالرغ من أن التصنيف العلمي للبحوث يشكل حافزاً للسعي نخو البحث الممتاز إلا أنه في الوقت نفسه قد يؤدي إلى إعطاء الأولوية للتميز في البحث العلمي بالتالي تضييق التزكيز وإهال جانب عم اخر اللتميز وهو (Kauppila, 2016: 34) الندريس

\subsubsection{2 التميز في أداء الطلبة}

تعمل المنظات التعليمية على تصميم البرامج والخدمات التعليمة التي تسهم في خلق قيمة متميزة للطلبة واصحاب المصلحة الاخرين بما يقود في النهاية إلى إستقطاب الطلبة للالتحاق بتاك المنظمة وتحتيق رضاهم ورضا اصحاب المصلحة الآخرين وضمان ولائهم وبالتالي تحقيق الاستدامة التنظيمة، إلا أن تحقيق مستويات عالية من الأداء التعليمي يتطلب مدخلاً للتعلم التنظيمي والشخصي للطلبة قائم على التشارك المعرفي من خلال عملية نظمية وهذا يعني أن عملية التعلم يجب أن (رشيد والزيادي،

:(214-213:2013

$$
\text { أ. تكون جزءاً من العمل اليومي للمنظمة النعليمية. }
$$

ب. تتم ممارستها على المستوى الشخصي، فرق العمل والمستوى التنظيمي. بشكل عام يجدر بالمنظات التعلمية التركيز على مخرجاتها المتثلة بالطلبة فالطالب الخريج هو الذي سيعس الصورة التعلمية التي انثثق منها والمنافس مع نظرائه من الخريجين من كليات أخرى، كما أن الطلبة المتميزين الذين تتوفر فيهم قدرات استثنائية

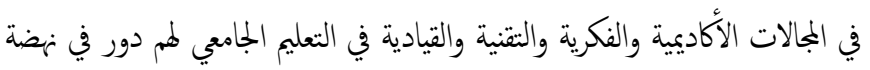
الامة وتطورها من خلال الاستفادة من ننائهم وافكارهم وادائهم المتميز (المدو،

. 373 :2016

\section{3. المبحث الثاني: منهجية الدراسة \\ 1.3 مشكلة الدراسة}

أصبحت قدرة المواقع الإلكترونية للجامعات على تقديم الخدمات بجودة عالية، ومدى استفادة مختلف الجهات من تلك الخدمات من أهم التحديات التي توابهها إدارة الجامعة وقياداتها. من جانب آخر فإن مجالات التميز الأكاديي أخذت صوراً وأشكلاً متعددة والتي كان لتكنولوجيا المعلومات والاتصالات التأثير البالغ والواضح في بروز تلك المجلات، مما حدا بالمؤسسات الأكاديمة ومنها الجامعات السعي لتبني عدد من
حول مفهومه الذي من الممكن أن يتمثل بالتدريسي المتميز أو ان يتحدد من خلال عوامل مثل الطبيعة الملهمة للندريسيين ، وتنظيم العروض التقديمية ، والثفاعل مع الطلبة كثركاء بالاضافة إلى مدى تلبية المعلومات المقدمة لأهداف العملية التعليمية، ويككن تقسيم التميز في الندريس إلى خمسة مراحل مترابطة مع بعضها وغياب احداها يلغي فائدة الآخر (13 - Brusoni et al.,2014:12) : أ. التميز في التدريس هو مفهوم متعدد الأبعاد وأبعاده المختلفة تتطلب أشكال مختلفة من التقدير والمكافأة. ب. إذاكان الحفاظ على جودة الندريس وتعزيزها واجب، فإن الاعتراف بالتميز في

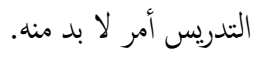

ج·إن معايير التميز الفردي في الندريس ليست أكثر صعوبة في التوضيح والتقييم من تلك المتعلقة بالتميز البحثي. ومع ذلك فهي أكثر تطوراً ما يقدره الأكاديميين التقليديين ولا يككن تطبيقها إلى حد ما طالما أن أولكك الذين يحكون على

$$
\text { التميز يفتقرون إلى التدريب لمهمته. }
$$

د. الشرط الأساسي لتميز الندريس الحتيقي على المستوى الفردي هو أن يكون القائم بههنة التدريس مدرب بشكل محترف وذلك من خلال ربط الكادر

$$
\text { الندريسي مباشرة بعملية تحليل التميز في التدريس. }
$$

هـ. التميز في التدريس الفردي هو شرط ضروري، ولكنه ليس شرطاً كافياً لتحقيق تجربة تعلم ممتازة للطالب فيجب أن يكون هناك تميز على مستوى الإدارات

$$
\text { والمنظمات أيضاً. }
$$

3.2.2.2 التميز في البحث العلمي يتطلب التميز في البحث العلمي توافر مجموعة معايير لتقييم للبحث المتميز من حيث الجودة والدقة والأصالة، وأن الغرض الأساسي من تحديد التميز هو ضمان الحصول عل التمويل الكافي من المنظات المالية المسؤولة عن تمويل البحوث الممثازة بكافة Brusoni et al.,2014: ( اشكلها من اجل الوصول إلى أداء بحثي بمستوى عالمي 12)، كما إنه من الممكن تحديد التميز البحثي لأي منظمة من خلال منشوراتها المستشهد بها بدرجة كيرة، عدد الجامعات العلمية ومنظات البحوث العامة فيها، 
- ..تفسير طبيعة ونوع العلاقة بين للجودة المدركة لخدمات الموقع الإلكتروني والتميز الأكاديمي في جامعة دهوك.

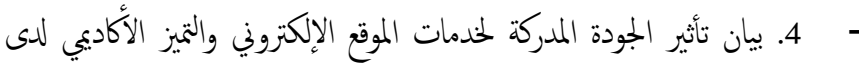
جامعة دهوك.

- التوصل الى مسببات مشكلة الدراسة وطرق معالجها او التخفيف منها.

\section{3 أهمية الدراسة}

تأتي أهمية الدراسة بكونها تناولت التعرف على أبعاد العلاقة الثأثرية للجودة المدركة لخدمات الموقع الإلكترونية في التميز الأكاديمي للجامعة، وذلك ضمن محاولة لبيان أهمية الجودة المدركة لخدمات الموقع الإلكترونية للوصول إلى تحقيق الرضا لدى المستفيدين من تلك الخدمات، وتقدم هذه الدراسة مساهمة متواضعة في مجال المعرفة العلمية بإعتبارها مرجعاً لطلبة الدراسات الأولية والعليا ولمككتبات الأكاديمة، فن الناحية النظرية تكمن الأهمية من خلال تناولها لمتغيرين يتم تناولما حديثاً في مجال البحث العلمي بالاضافة الى ربطها لمتغرات الدراسة بعلاقات احصائية تفسر العلاقة والثأثير ببنها مما يجعلها ذات فائدة علمية لكل من الباحثين، الطلبة، والكاديمين الذين يرغبون بدراسة اي من متغيرات الدراسة الحالية. ومن الناحية الميدانية تكتسب الدراسة أهميتها في توجيه الجامعات للعمل نخو تحسين جودة خدماتها الإلكترونية المدركة من قبل المستفيدين والمتعاملين معها، وبيان مدى أهمية ذلك في إنعكاتها على مستوى التميز الأكاديمي والتي تسعى إليه من ضمن أهدافها الاستراتيجية والذي يعُد نقطة قوة تنافس بها الجامعات الماثلة، وذلك من خلال نناجُ ومقترحات تسهم في رسم الخطى السلمة في بناء مواقع الكترونية ذات جودة عالية تساعد في إثراء

$$
\text { الجامعات بمستوى أكاديمي تمتيز. ف }
$$

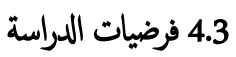

$$
\text { تسعى الدراسة إلى اختبار الفرضيات الآتية: }
$$

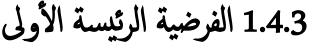

لا توجد علاقة معنوية وذات دلالة احصائية بين الجودة المدركة للخدمات الموقع

$$
\text { الإلكتروني والتميز الأكاديمي لدى التدريسيين في جامعة دهوك. }
$$

تلك المجالات وتسخير ما تمتلكه من موارد مختلفة من اجل أن تحقق التميز الذي يجعلها في موقع تنافسي متقدم مع الجامعات المنافسة. عليه تتمحور تساؤلات المشكلة في مضامين كل من جودة خدمات الموق الإلكتروني لجامعة دهوك والمدركة من قبل المستفيدين بمختلف مستوياتهم الفكرية والعلمية والتخصصية، وكذلك التميز الأكاديمي الذي تحققه الجامعة والذي يستمد مضامينه من إدراك المستفيدين لجودة خدمات الموق الإلكتروني. لذا فإن التساؤل الرئيس لمشكة الدراسة يتثل في: هل أن الجودة المدركة لخدمات الموقع الإلكتروني للجامعة تؤثر في مستويات التميز

الأكاديمي لها ؟ أن

وبناءً على ما سبق يككن تلخيص مشكلة الدراسة في التساؤلات الفرعية الآتية: - هل تتوافر مقومات او ابعاد الجودة المدركة لخدمات الموقع الإلكتروني في

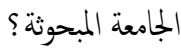

- هل تتوافر مجالات او ابعاد المتيز الأكاديي في الجامعة المبحوثة؟ - هل تتبنى الجامعة المبحوثة مستويات معينة من الجودة المدركة لخدمات الموقع

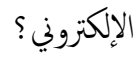
- هل تتبنى الجامعة المبحوثة مستويات معينة من التميز الأكاديمي؟ - هل توجد علاقة بين الجودة المدركة للدمات الموقع الإلكتروني والتميز الأكادييي وأبعادها في جامعة دهوك حسب اراء العينة المبحوثة؟ - هل يوجد تأثير لأبعاد الجودة المدركة لخدمات الموقع الإلكتروني في أبعاد التميز

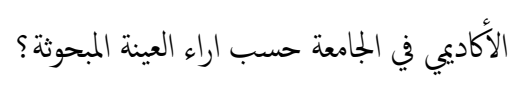

\section{3}

في ضوء ما تم إستعراضه في مشكلة الدراسة وتساؤلاتها فإن أهداف الدراسة يككن

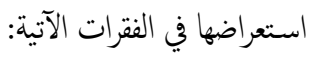
- عرض المفاهيم الرئيسة لمتغيرات الدراسة وأبعادها وتوضيح الجوانب المتصلة بها وما تناولته الدراسات السابقة في هذا الجمال. - 2.تشخيص مستويات تبني جامعة دهوك واهتاهما بكل من للجودة المدركة

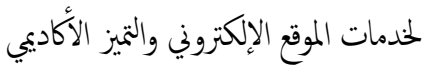




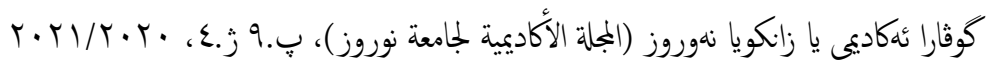

\section{4. المبحث الثالث: الجانب الميداني للدراسة}

2.4.3 الفرضية الرئيسة الثانية

1.4 وصف متغيرات الدراسة

توضح النتائج في الجدول (2) استجابات افراد العينة المبحوثة تجاه متغيرات الدراسة

$$
\text { وكالآتي: }
$$

الجودة المدركة لخدمات الموقع الإلكتروني: يوجد تفاوت في استجابات الأفراد

المبحوثين تجاه أبعاد الجودة المدركة لخدمات الموقع الإلكتروني حيث جاء بُعد

الخصوصية بالمرتبة الاولى وبمتوسط حسابي قيمنه (2.22) وبانحراف معياري

بلغ(0.63)، يليه بُعد سهولة الإستخدام ثم جودة المعلومات وأخيراً بُعد

$$
\text { الإستجابة (سرعة الوصول). }
$$

التميز الأكايعي: يوجد تباين في استجابات المبحوثين عينة الدراسة تجاه أبعاد التميز الأكاديم، إذ تشير المتوسطات الحسابية إلى أن هناك أهتام ببعد التميز في البحث العلمي والذي احتل المرتبة الأولى وبمتوسط حسابي (1.97) وانخراف معياري(0.77)،بينا جاء بُعد التميز في التدريس في المرتبة الآخيرة

$$
\text { بمتوسط حسابي (1.87) وبلغ الإخراف المعياري(0.78) }
$$

\begin{tabular}{|c|c|c|c|c|c|c|c|c|c|}
\hline \multirow{3}{*}{ 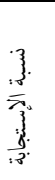 } & \multirow{3}{*}{ 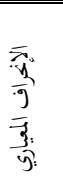 } & \multirow{3}{*}{$\begin{array}{c}\overline{7} \\
3 \\
-1 \\
-3 \\
-3 \\
-3:\end{array}$} & \multicolumn{6}{|c|}{ مقياس الاستجابة } & \multirow{3}{*}{ الأبعاد } \\
\hline & & & \multicolumn{2}{|c|}{ لا اتفق } & \multicolumn{2}{|c|}{ غير متاكد } & \multicolumn{2}{|c|}{ اتقق } & \\
\hline & & & $\%$ & ت & $\%$ & ت & $\%$ & ت & \\
\hline 0.67 & 0.74 & 2.01 & 27.84 & 49 & 43.47 & 76.50 & 28.92 & 50.50 & سرعة الوصول \\
\hline 0.73 & 0.75 & 2.18 & 22.01 & 38.71 & 39.51 & 66.64 & 41.7 & 69.36 & سهولة الاستخدام \\
\hline 0.74 & 0.63 & 2.22 & 12.08 & 21.25 & 53.34 & 93.88 & 34.59 & 60.88 & لضصوصية \\
\hline 0.70 & 0.74 & 2.10 & 23.51 & 41.36 & 42.66 & 75.09 & 32.90 & 57.91 & جودة المعلومات \\
\hline 0.65 & 0.77 & 1.94 & 33.01 & 58.08 & 39.83 & 70.08 & 27.19 & 47.83 & التميز بالادارة \\
\hline 0.62 & 0.78 & 1.87 & 39.52 & 69.55 & 34.36 & 60.44 & 26.13 & 46 & التميز بالتدريس \\
\hline 0.66 & 0.77 & 1.97 & 31.97 & 56.25 & 38.83 & 68.33 & 29.22 & 51.41 & \\
\hline 0.63 & 0.78 & 1.89 & 36.61 & 64.44 & 37.81 & 66.56 & 25.59 & 45 & الطميلة في اداء \\
\hline 0.68 & 0.75 & 2.02 & 28.32 & 49.83 & 41.23 & 72.19 & 30.78 & 53.61 & شر الكلي \\
\hline
\end{tabular}

$$
\text { الجدول } 2
$$$$
\text { وصف متغيرات الدراسة }
$$

المصدر: إعداد الباحثة بالإعتاد على خخرجات البرنامج الإحصائي (Spss).
لا يوجد تأثير معنوي ذي دلالة احصائية للجودة المدركة لخدمات الموقع الإلكتروني في التميز الأكاديمي لدى التدريسيين في جامعة دهوك.

5.3 وصف مجتمع الدراسة

يُعد تحديد مجتمع الدراسة المناسب من النقاط الأساسية التي تدع نجاح البحث العلمي وذلك بإعتباره المصدر الأساس للبيانات التي ستخضع للتحليل والتي ينتج عنها حصيلة النتأجُ التي توصلت إلهيا الدراسة، بناءاً على ذلك إختارت الباحثة الندريسيين في جامعة دهوك كمتنع للدراسة بإعتبارهم الفئة الأنسب لتحديد مضامين الدراسة الحالية.وشملت العينة بمحوعة من التدريسيين في كليات جامعة دهوك والبالغ عددها (18) كلية، حيث وُزعت (300) إستارة إستبانة على أفراد العينة، أُسترجع منها (189) حيث بلغت نسبة الإستعادة (63\%) ، وبلغ عدد

\begin{tabular}{|c|c|c|c|c|}
\hline النسبة \% & العدد & الفئة & الخصائص & ت \\
\hline 65.9 & 116 & ذ5 & \multirow{4}{*}{ الجنس الجن } & \\
\hline 34.1 & 60 & أنثى & & 1 \\
\hline 100 & 176 & الجمموع & & \\
\hline 8.5 & 15 & أقل من 30 سنة & & 2 \\
\hline 47.2 & 83 & أقل من 40 سنة & \multirow{4}{*}{ العمر - ل العم } & \\
\hline 44.3 & 78 & اكثر من 40 سنة & & \\
\hline 100 & 176 & الجموع & & \\
\hline 36.4 & 64 & دكتوراه & & \\
\hline 55.7 & 98 & ماجستير & \multirow{4}{*}{ (الشهادة) الدراسي } & 3 \\
\hline 8 & 14 & بكالوريوس & & \\
\hline 100 & 176 & الجمموع & & \\
\hline 1.7 & 3 & أستاذ & & \\
\hline 19.9 & 35 & أستاذ مساعد & \multirow{5}{*}{ اللقب العلمي } & 4 \\
\hline 36.9 & 65 & 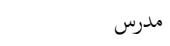 & & \\
\hline 41.3 & 73 & مدرس مساعد & & \\
\hline 100 & 176 & الجموع & & \\
\hline 51.7 & 91 & إنساني & & \\
\hline 48.3 & 85 & علمي & \multirow[t]{3}{*}{ التخصص } & 5 \\
\hline 100 & 176 & الجمموع & & \\
\hline 13.1 & 23 & أقل من 5 سنوات & & 6 \\
\hline 29 & 51 & أقل من 10 سنوات & \multirow{3}{*}{ عدد سنوات الخدمة } & \\
\hline 58 & 102 & 10 سنوات فآكتر & & \\
\hline 100 & 176 & الجمموع & & \\
\hline
\end{tabular}
الإستمارات الصالحة للتحليل (176) إستارة وبذلك بلغت نسبة الإستجابة

$$
\text { (59\%)، ويوضح الجدول (1) وصف الأفراد المبحوثين حسب ساتهم الشخصية. }
$$

$$
1 \text { الجدول } 1
$$




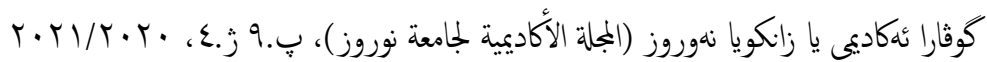

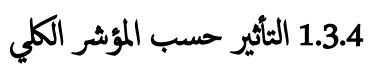

2.4 علاقات الارتباط

تشير ننائُ تحليل البيانات الميدانية الموجودة في الجدول (4) إلى وجود تأثير معنوي للجودة المدركة لخدمات الموقع الإلكتروني في التميز الأكاديي وعلى مستوى المؤشر الكلي لها، إذ بلغت قيمة (P-Value) المحسبة (0.000) وهي أقل بكثير من قيمة مستوى المعنوية الافتراضي والذي اعتمدته الدراسة والبالغ (0.05)، ويدع ذلك أن قيمة (F) المحسوبة والبالغة (131.548) كانت أكبر من قيمها الجدولية والبالغة (3.895) وبدرجات حرية (1، 174) ما يشير إلى معنوية الثأثير وعند مستوى (0.05)، وتشير نناجُ التحليل على المستوى الكلي إلى الآتي: أ. في ضوء معادلة الانحدار تبين قيمة الثابت (B) والبالغة (0.179) أن هناك ظهوراً للميز الأكاديمي من خلال أبعاده مقداره (0.179) وذلك عندما تكون قيمة الجودة المدركة لخدمات الموقع الإلكتروني ومن خلال أبعادها المساوية للصفر. فيمكن تفسير هذه النتيجة بأن التميز الأكاديمي يستقي جزء من سماته من الجودة المدركة التي توفرها خدمات الموقع الإلكتروني للجامعة. ب. أما قيمة الميل الحدي (B) فقد بلغت (0.656) وهي دلالة على أن تغيراً مقداره واحد (1) في متغير الجودة المدركة لخدمات الموقع الإلكتروني سيؤدي بالتبعية إلى تغير مقداره (0.656) في التميز الأكاديي، وهو تغير كير يككن الاستناد إليه في تفسير العلاقة التأثيرية للمتغير المستقل الجودة المدركة لخدمات الموقع الإلكتروني في المتغير المتمد التميز الأكاديمي. أما قيمة (R2) فقد بلغت (0.431) والتي تشير إلى أن ما سبته (43.1\%) من التغير الذي يطرأ على التميز الأكاديمي يكن أن نغزوه إلى الجودة المدركة لخدمات الموقع الإلكتروني، أي أن القيمة التفسيرية للمتغير المستقل فيا يحدث للمتغير المعتمد بلغت (43.1\%)، كما تشير هذه النتيجة إلى أن النسبة الثأثيرية المتبقية والبالغة (56.9\%) تعود لعوامل تأثيرية أخرى غير مضمنة في الأنموذج الافتراضي للدراسة.
يتضح من معطيات الجدول (3) نتائج علاقات الارتباط بين متغيرات الدراسة إذ تبين وجود إرتباط معنوي وموجب وبمستويات عالية بين المتغير المستقل (الجودة المدركة لحدمات الموقع الإلكتروني) والمتغير المعتمد (التميز الأكاديمي)، حيث بلغت قيمة معامل الإرتباط بنهها (0.656) وهي قيمة معنوية عند مستوى (0.01) مما يعني رفض فرضية الارتباط الخاصة بالدراسة الحالية والتي تنص على أنه (لا توجد علاقة معنوية وذات دلالة احصائية بين الجودة المدركة لخدمات الموقع الإلكتروني والتميز الأكاديمي لدى الندريسيين في جامعة دهوك)، وتقبل الفرضية البديلة التي تنص على تلى أنه (توجد علاقة معنوية وذات دلالة احصائية بين الجودة المدركة لخدمات الموقع الإلكتروني والتميز الأكاديمي لدى التدريسيين في جامعة دهوك). الجدول

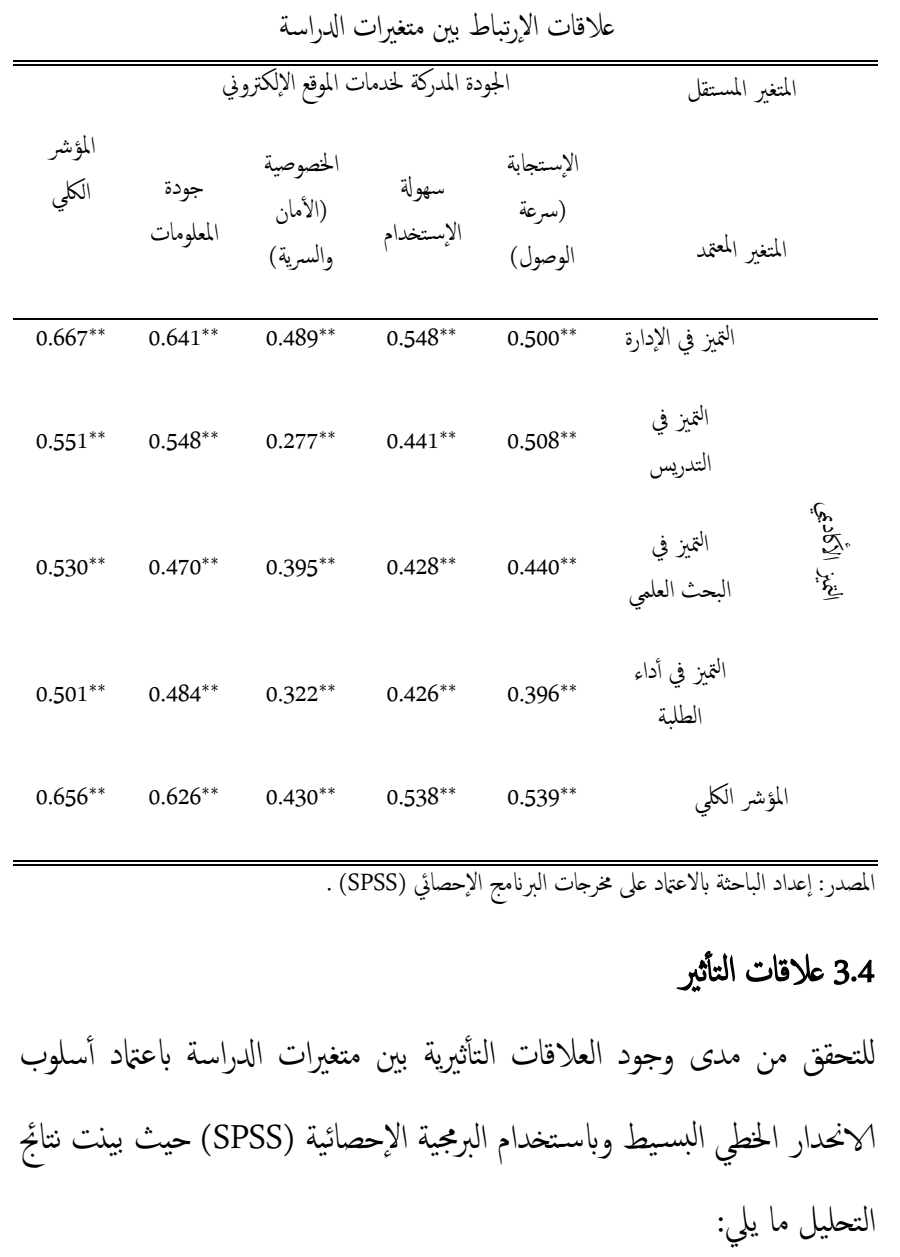




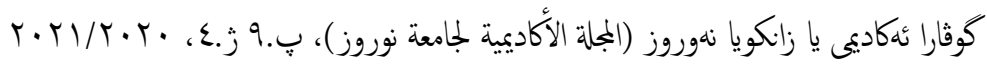

بكثير من مستوى المعنوية الافتراضي للدراسة والبالغ (0.05). ويؤكد معنوية هذا التأثير قيمة (t) المحسوبة والبالغة (6.740) و (3.766) وهي الكبر من قيمها الجدولية البالغة (1.6537) وبدرجة حرية (173). كما أن قيمة (R) بلغت (0.438) أي أن الأموذج الثاني يفسر مانسبته (43.8 \%) من التغير الحاصل في التميز الأكاديي يعود للجودة المدركة للدمات الموقع الإلكتروني المتثثلة بجودة المعلومات وسرعة الوصول. وبناءاً على ذلك ترفض الفرضية الرئيسة الثانية والتي تنص على أنه (لا يوجد تأثير معنوي ذي دلالة احصائية للجودة المدركة لخدمات الموقع الإلكتروني في التميز الأكاديمي لدى التدريسيين في جامعة دهوك)، وتقبل الفرضية البديلة والتي تنص على أنه (يوجد تأثير معنوي ذي دلالة احصائية للجودة المدركة لخدمات الموقع الإلكتروني في التميز الأكاديمي لدى التدريسيين في جامعة دهوك).

$$
5 \text { الجدول }
$$

تأثير أبعاد الجودة المدركة لخدمات الموقع الإلكتروني في التميز الأكاديي

\begin{tabular}{|c|c|c|c|c|c|}
\hline $\begin{array}{l}\text { P- قلمحسوبة } \\
\text { Value } \\
\text { المحسة }\end{array}$ & قيمة t المحسوبة & $\begin{array}{l}\text { قيمة } \\
R^{2}\end{array}$ & $\begin{array}{l}\text { قيمة } \\
\text { B }\end{array}$ & المتغيرات & الأموذج \\
\hline- & - & - & (0.655) & - & الثابت \\
\hline$(0.000)$ & (10.588) & $(0.392)$ & $(0.599)$ & جودة المعلومات & 1 \\
\hline - & - & - & $(0.455)$ & - & الثابت \\
\hline$(0.000)$ & $(6.740)$ & $(0.438)$ & $(0.452)$ & جودة المعلومات & \\
\hline$(0.000)$ & $(3.766)$ & & $(0.254)$ & الإستجابة (سرعة & 2 \\
\hline
\end{tabular}

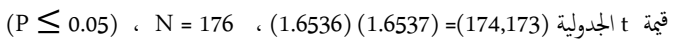

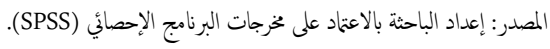

\section{5. المبحث الرابع: الاستناجات والمقترحات}

\section{5 الاستنثاجات}

تبين وجود اختلاف في آراء عينة الدراسة تجاه وصف كل بُعد من أبعاد الجودة المدركة لخدمات الموقع الإلكتروني إذ كانت أعلى نسبة اتفاق على بُعد سهولة الإستخدام والتي تؤكد على إهتمام الجامعة بتقديم التسهيلات الكافية لإستخدام
الجدول (4)

تأثير الجودة المدركة لخدمات الموقع الإلكتروني في التميز الاكاديي

\begin{tabular}{|c|c|c|c|c|c|}
\hline $\begin{array}{c}\text { قيمة P-Value } \\
\text { المسوبة }\end{array}$ & 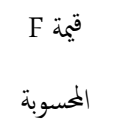 & ق قيمة R & قيمة B & ق ق ق ق ق Bمة & الأمثوذج \\
\hline - & - & - & - & 0.179 & الثابت \\
\hline 0.000 & 131.548 & 0.431 & 0.656 & 0.816 & الجودة المدركة لمدمات \\
\hline & $(\mathrm{P} \leq 0.05)$ & & $\mathrm{N}=176$ & 3.895 & قيمة F الجدولية (1، 174) = \\
\hline
\end{tabular}

تم تطبيق تحليل الانحدار المتعدد وبطريقة (Stepwise) للتعرف على المستويات التأثرية لأبعاد الجودة المدركة لخدمات الموقع الإلكتروني في التميز الأكاديي للتدريسيين، وكانت نناجُ التحليل قد أفرزت أنموذجين للإنحدار وبحسب معطيات

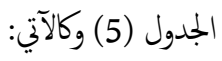

أ. الأثموج الأول: يتضمن هذا الأثموجج متغيراً واحداً وهو جودة المعلومات حيث أشارت نتائج التحليل إلى أن لهذا البعد تأثيراً أعلى من باقي أبعاد الجودة المدركة لحدمات الموقع الإلكتروني في التميز الأكاديي حيث تشير قيمة (P-Value) المعنوية الافتراضي للدراسة والبالغ (0.05). ويؤكد معنوية هذا التاثثير قيمة (t) المحسوبة والبالغة (10.588) وهي أكبر من قيمها الجدولية البالغة (1.6536) وبدرجة حرية (174). أما قيمة (R2) فقد بلغت (0.392)، أي أن الأثموج الأول يفسر ما سبته (39.2\%) من النغير الحاصل في التميز الأكاديي والذي يعود للجودة المدركة لحدمات الموقع الإلكتروني وبالنات لبُعد

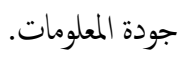
ب. الأموذج الثاني: يتضمن هذا الأموذج متغيرين وها جودة المعلومات والإستجابة (سرعة الوصول) حيث أشارت نتائج التحليل إلى أن لهذه الأبعاد تأثيراً اكبر من باقي أبعاد الجودة المدركة لخدمات الموقع الإلكتروني في التميز الأكاديي إذ تشير قيمة (P-Value) المحسوبة إلى (0.000) وهي قيمة أقل 
كوفارا ئهكاديى يا زانكويا نهوروز (الجلة الأكاديمية لجامعة نوروز)، ت.

بقيام الجامعة بتوفير بنية تحتية تكنولوجية متطورة تدع التميز لكادرها التدريسي، كلمراكز الخاصة بقديم كافة متطلبات القيام بالبحث العلمي. ضرورة تبني الجامعة لمعايير التقييم المعتمدة ضمن التصنيف الجامعي الوطني لإقليم كوردستان العراق (NUR) من أجل الوصول للمستوى المطلوب

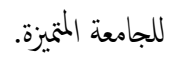

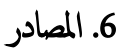

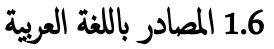

\subsection{6 الرسائل والاطاريح الجامعية}

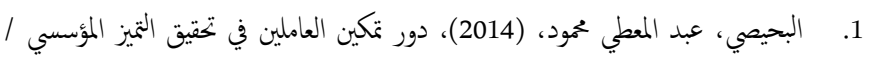

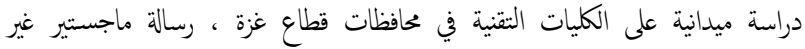

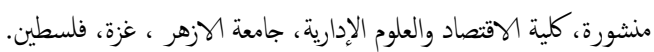
حسين، أيمان محود محمد، (2011)، قياس جودة الخدمات الإلكترونية بإستخدام مدخل

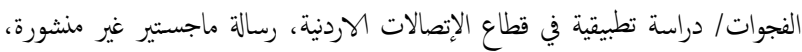

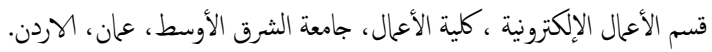

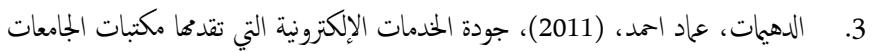

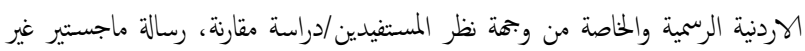

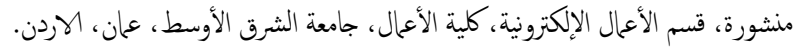

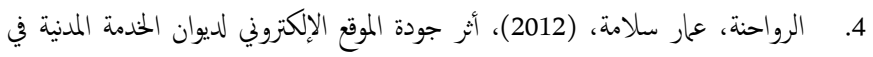
تحتيق رضا العاملين في إدارة الموارد البشرية في المنظات الخاضعة لنظام الخدمة المدنية في الماني

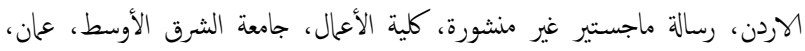
الاردن.

5. الشهاني، نورة عبدالله حزام، (2017)، دور إدارة الكفاءات الأكاديمة في تحقيق التميز

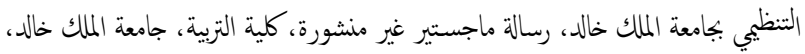

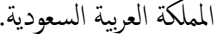

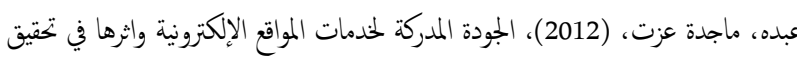

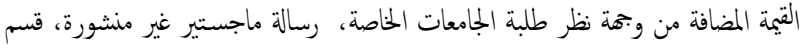

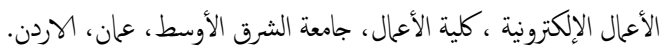

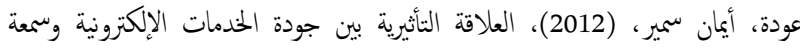

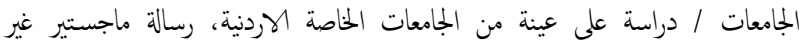

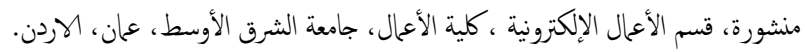

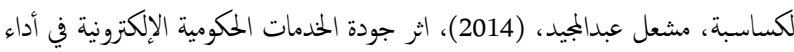

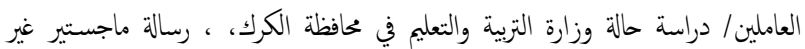

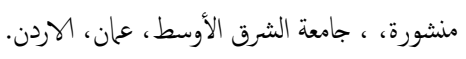

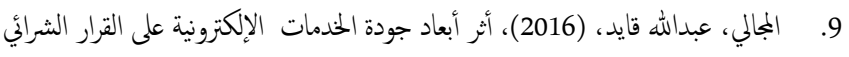

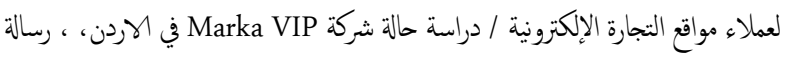

الموقع الإلكتروني لها بالشكل الذي يساهم في إنجاز المستفيدين لمهاهم بسهولة وبالتالي توفير خبرة إيجابية لمم للتعامل مع المواقع الأخرى. تبين أن أغلبية أفراد العينة من التدريسيين أنقسموا بين من هم غير متفق أو غير متاكد تماماً من مدى توفر التميز الأكاديمي في كليات الجامعة، مما يعطي إثارة واضحة إلى وجود خلل في تبني الجامعة لإستراتيجيات تعزيز التميز

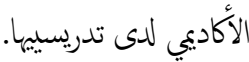
أوضحت نتائُ التهليل بأن أقوى علاقات الإزتباط بين أبعاد الجودة المدركة لخدمات الموقع الإلكتروني للجامعة وأبعاد التميز الأكاديي كانت لبُعد جودة المعلومات، وبُعد التميز في الإدارة أي أنه كلما إزداد تركيز الجامعة على ردي مستويات الجودة في المعلومات التي يقدما موقعها الإلكتروني كلما إنعكس ذلك عل تحسين وتعزيز مستويات التميز لكوادرها التدريسية. هنالك تأثير إيجابي بمستويات معنوية لمتغير الجودة المدركة لحدمات الموقع الإلكتروني للجامعة في متغير التميز الأكاديي، وبحسب ما أفرزته مؤشرات التحليل على المستوى الكلي، مما يثير إلى أن إهتمام الجامعة بتحسين جودة الموقع الإلكتروني يسهم في تعزيز مستويات التميز الأكاديي للتدريسيين لديها. توصلت الدراسة إلى أن هناك مستويات معنوية عالية من التلازم بين الجودة المدركة لخدمات الموقع الإلكتروني للجامعة والتميز الأكاديي لدى التدريسيين، مما يشير إلى أنه كلما زاد إهتام الجامعة في توفير خدمة ذات مستوى عالي من الجودة على موقعها الإلكتروني كلما إنغكس ذلك على إرتفاع مستويات التميز الأكاديمي لديها.

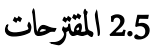

قيام الجامعة بوضع معايير الموقع الإلكتروني تضمن تقديم الخدمة إلى التدريسيين بشكل ممتاز وبالدقة والسرعة التي يتوقعونها فضلاً عن تنويع الخدمات المقدمة. على الجامعة أن تأخذ بالحسبان عند قياما بعملية تحسين أبعاد الجودة المدركة لخدمات الموقع الإلكتروني الأهمية الترتيية لتاك الأبعاد ووفقاً لما افرزته ننائج الدراسة الحالية. 


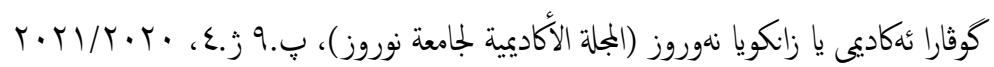

University), International Journal on advanced Sience Engineering Information Technology, Vol. 7, No. 3.

7. Othmani, Leila, and Bouslama, Néji, (2015), Perceived Quality of a Virtual Community and Its Components: An Exploratory Investigation, Journal of Internet Social Networking and Virtual Communities, Vol. 2015.

8. Parasuraman, A., Zeithaml, Valarie A., and Malhotra, Arvind, (2005), E-S-QUALA Multiple-Item Scale for Assessing Electronic Service Quality, Journal of Service Research, Volume 7, No. X.

9. Porral, Cristina Calvo, Mangin, Jean-Pierre Le'vy, and Corti, Isabel Novo, (2013), Perceived quality in higher education: an empirical study, Marketing Intelligence and Planning Journal ,Vol. 31, No. 6.

10. Raluca, Gheorghe Iuliana, Mădălina, Gheorghe Consuela, and Lorin, Purcărea Victor, (2018), Measuring the perceived quality of ophthalmology services in private organizations/A marketing perspective, Romanian Journal of Ophthalmology, Vol. 62, Issue 1.

11. Rolland, Sylvie Desmet, Pierre, (2007), Perceived quality in a multi-channel environment: Impact of website visits on perceived instore quality, (HAL-SHS) Sciences de l'Homme et de la Société Journal, Vol.1.

12. Sife, Alfred Said, and Msoffe, Grace Emanuel, (2013), Userperceived Quality of Selected Tanzanian Public University Websites, Library Philosophy and Practice (e-journal), P. 950.

13. Vieira, PauloRoberto, Troccoli, Irene Raguenet, and da Silva, JoséCarvalho, (2012), Perceived Quality In Higher Education Service In Brazil:, InterSciencePlace Journal.

\subsubsection{Conferences}

1. Varlamova1, Alla I., (2016), Academic excellence in the age of information technology, SHS Web of Conferences 9, 01075 (2016), Moscow, Russia .

\subsubsection{Books}

1. ltbach, Philip G. , Salmi, Jamil , (2011), The Road to Academic Excellence, The International Bank for Reconstruction and Development / The World Bank 1818 H Street NW, Washington, USA.

2. Brusoni, M.; Damian, R.; Sauri, J.G.; Jackson, S.; Komurcugil, H.; Malmedy, M.; Motova, G.; Pisarz, S.; Pol, P.; Rostlund, A.; Soboleva, E.; Tavares, O. \& Zobel, L., (2014), The Concept of

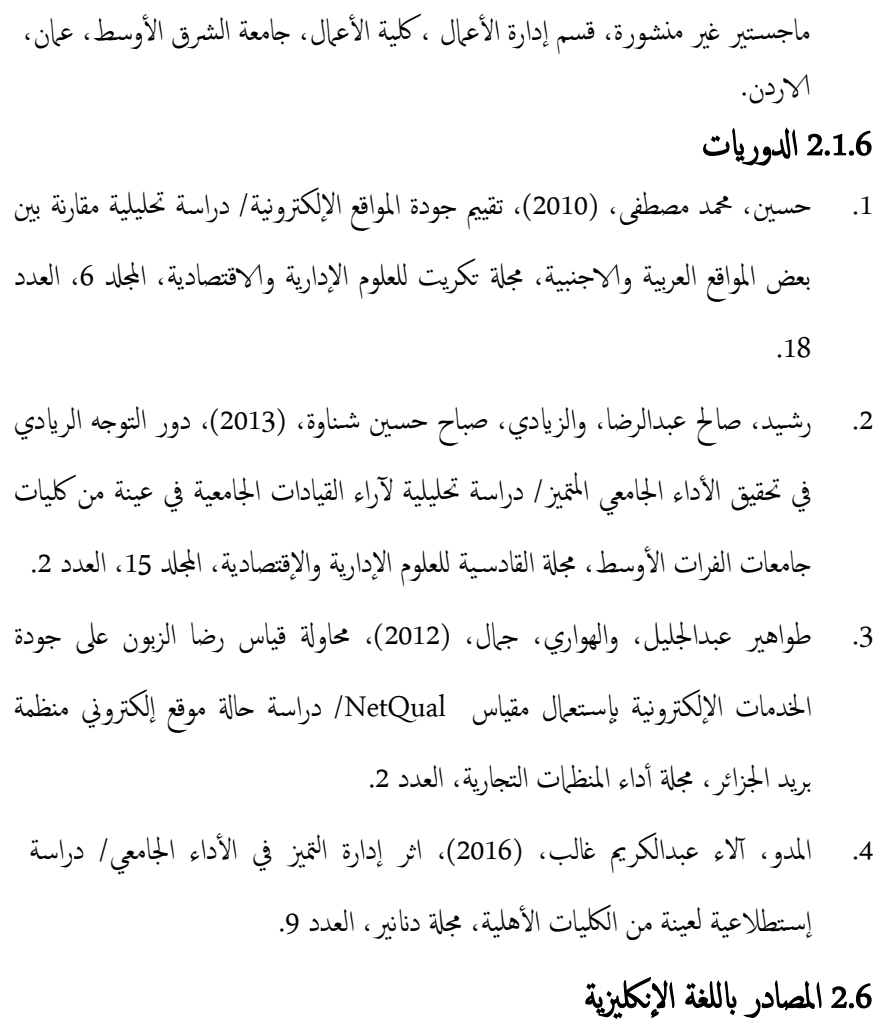

\subsubsection{Journals and Periodical}

1. Alkhouli, Samer, (2018), The Effect of Banks Website Service Quality and E-satisfaction on E-loyalty: An Empirical Study on Swedish Banks, International Journal of Business and Management, Vol. 13, No. 1.

2. Al-zoubi, Ali Falah, AlShoura, Mohammad,and Oudh, Ayman, (2018), The Impact of Private Universities' Websites Services' Qualityon the Reputation in Jordan (An Applied Study), International Business Research Journal, Vol. 11, No.1.

3. Berghout, Abdelaziz, (2011), Educational Excellence in The Islamic World: Enhancing Global Quality and Strategy Planning, Arab Journal For Quality Assurance in Higher Education, Vol. 4, No.8.

4. Connolly, Regina, Bannister, Frank, and Kearney, Aideen, (2010), Government website service quality: a study of the Irish revenue online service, European Journal of Information Systems, Vol. 19.

5. Muhammed, Abdulrahman, and Yusuf, Lamidi , (2016), Manufacturers' perceived quality of electricity service and organizational performance in Nigeria, Journal of Transportation and Logistics, Vol. 1, No.2.

6. Napitupulu, Darmawan, (2017), Analysis of Factors Affecting the Website Quality Based on Webqual Approach (Study Case: XYZ 


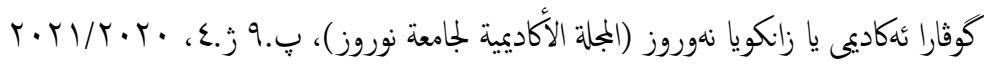

Excellence in Higher Education, European Association for Quality Assurance in Higher Education AISBL, Brussels, Belgium.

3. Hidayanto, Achmad Nizar, Rofalina, Fanny, Handayani, Putu Wuri, (2015), Influence of Perceived Quality of Official University Websites to Perceived Quality of University Education and Enrollment Intention, IGI Global book series Advances in EBusiness Research (Business Science Reference), U.S.A.

4. Kauppla, Osmo, (2016), Integrated Quality Evaluation In Higher Education, University of Oulu, Acta Univ. Oul. , Finland. 


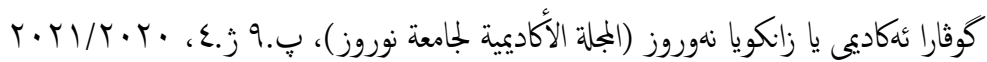

\title{
إستبانة البحث
}

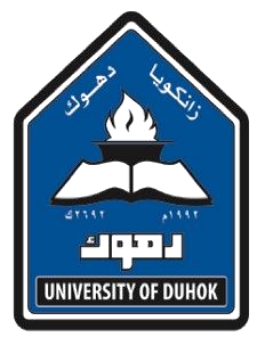

\author{
جامعة دهوك \\ كلية الإدارة والاقتصاد \\ قسم إدارة الأعمال

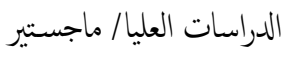

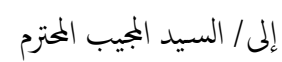

م/ استمارة استبانة

تمية طيبة..........

آمل أن تقدم جزءاً من وقتك الثمين في الإجابة على فقرات الاستبانة التي بين يديك، شاكةًة لك حسن التعاون، وثقتي كبيرة في حرصك على الإجابة بموضوعية تامة عن جميع

$$
\text { الفقرات الواردة فهيا. }
$$

إن الغرض من هذه الاستبانة هو قياس متغيرات الرسالة المعنونة بـــ الجودة المدركة لخدمات الموقع الإلكتروني للجامعة وأثرها في تعزيز التميز الآكاديي/ دراسة استطلاعية لآراء عينة من التدريسيين في جامعة دهوك". وهي جزء من متطلبات نيل شهادة الماجستير في إدارة الأعمال/كلية الإدارة والاقتصاد في جامعة دهوك، يرجى التفضل بمل؛ فقرات الاستبانة، علماً بأنه سيتم التعامل مع إجاباتكم بسرية تامة خدمةً لأهداف البحث العلمي شكراً لوقتكم الثمين الذي منحتموني إياه وتقبلوا منا فائق الشكر والامتنان......

$$
\begin{gathered}
\text { د.سعد فاضل عباس المحمود } \\
\text { أستاذ مساعد }
\end{gathered}
$$

الباحثة

أثين إدريس سعدون إساعيل 
كوثارا ئهكاديى يا زانكويا نهوروز (الجملة الأكاديمة لجامعة نوروز)، ت.

أولاً: بيانات تعريفية

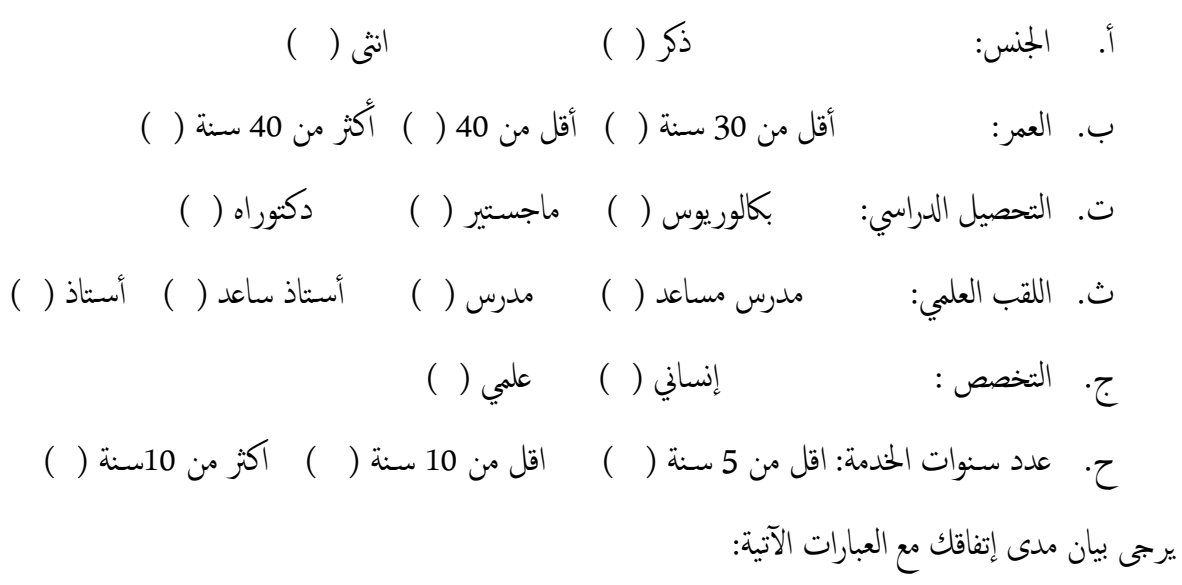

كانيأ: الجودة المدركة لخدمات الموقع الككتروني للجامعة

درجة ادراك المستفيد لجودة الخدمة المقدمة من قبل الموقع الإلكتروني لجامعته من خلال مقارنة اداء الخدمة الفعلي مع التصور المسبق لديه عن جودة تلك الخدمة، والمتمثلة بالابعاد التالية: سرعة الوصول، سهولة الاستخدام، الخصوصية (الامان والسرية)، جودة المعلومات.

\begin{tabular}{|l|l|l|l|l|}
\hline & & & \\
\hline & & & \\
\hline
\end{tabular}




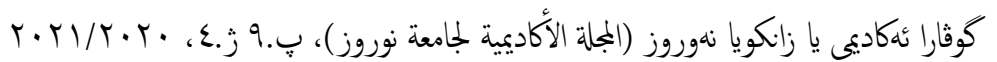

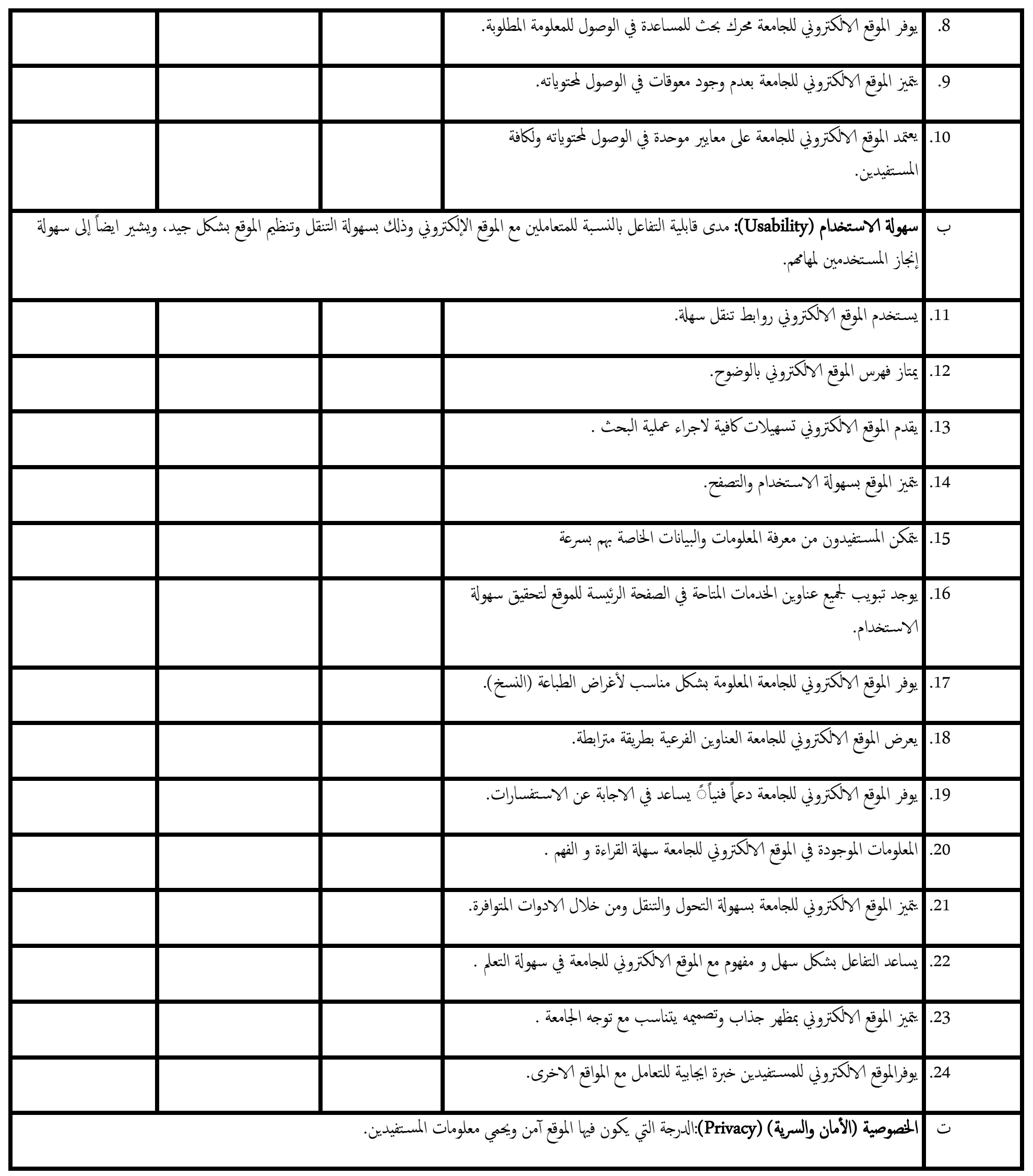




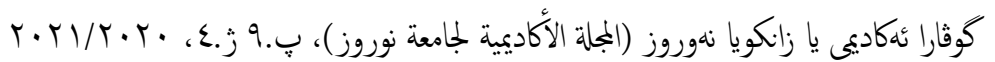

\begin{tabular}{|c|c|c|c|}
\hline & & يتم استخدم كلمات المرور في الموقع الكاكتروني للجامعة كنها وسيلة آنة. & .25 \\
\hline & & يحقق الموقع الالكتروني اتصالات امنة بين المستفيدين والجامعة. & .26 \\
\hline & & يتم اطلاع المستفيدين على سياسات وتفاصيل اجراءات الامان في الموقع الاككتروني. & .27 \\
\hline & & يضمن الموقع الاكتروني للجامعة سرية المعلومات الخاصة بالمستفيدين. & .28 \\
\hline & & يعتمد الموقع الاككتروني اجراءات خاصة لماية حسابات المستفيدين من الاختزاق. & .29 \\
\hline & & تسهم اجراءات الامان والسرية للموقع الاككتوني على زيادة ثقة المستفيدين. & .30 \\
\hline & & يعتمد الموقع الاككتروني للجامعة عدداً من الآليات لمماية واخفاء تنقل المستفيدين فيه. & .31 \\
\hline & & يعتمد الموقع سياسة عدم مشاركة معلومات المستفيدين مع المواقع الأخرى. & .32 \\
\hline \multicolumn{3}{|c|}{ مجيارة الموقع. المعلومات (Information quality): يقاس هذا البعد بكفاية وشمول المعلومات أي حصول المستخدم على معلومات دقيقة وكاملة وواضحة وذات مصداقية عند } & $\dot{4}$ \\
\hline & & تتصف المعلومات المتوافرة في الموقع الككتروني للجامعة بكونها دقيقة. & .33 \\
\hline & & يتم تحديث المعلومات المتوافرة في الموقع الاككتوني للجامعة بصورة دائمة. & .34 \\
\hline & & $\begin{aligned} \text { يوفر الموقع الاكتروني للجامعة نماذج مناسبة لعرض المعلومات على سبيل المثال } \\
\text { (Pdf , power point, Word) }\end{aligned}$ & .35 \\
\hline & & يقدم الموقع الاككتروني للجامعة معلومات كاملة حول الخدمات التي يجتاجما المستفيدين. & .36 \\
\hline & & ترتبط المعلومات المتوافرة في الموقع الكلكتروني بطبيعة الخدمات التي تقدها الجامعة. & .37 \\
\hline & & يعرض الموقع الاككتوني للجامعة معلومات حديثة تناسب التوقيت المطلوب. & .38 \\
\hline & & يستبدل الموقع الاككتوني للجامعة المعلومة القديمة بعد انتهاء وقتها بعلومة جديدة. & .39 \\
\hline & & يتم عرض مناجه الدراسة للجامعة في الموق الاكتروني بشكل واضح و دقيق. & .40 \\
\hline & & تعمل جميع الروابط الموجودة في الموقع بشكل جيد و تحتوي معلومات وافية و دقيقة. & .41 \\
\hline & & يوفر الموقع الاككتروني معلومات متاحة لكافة المستفيدين. & .42 \\
\hline
\end{tabular}




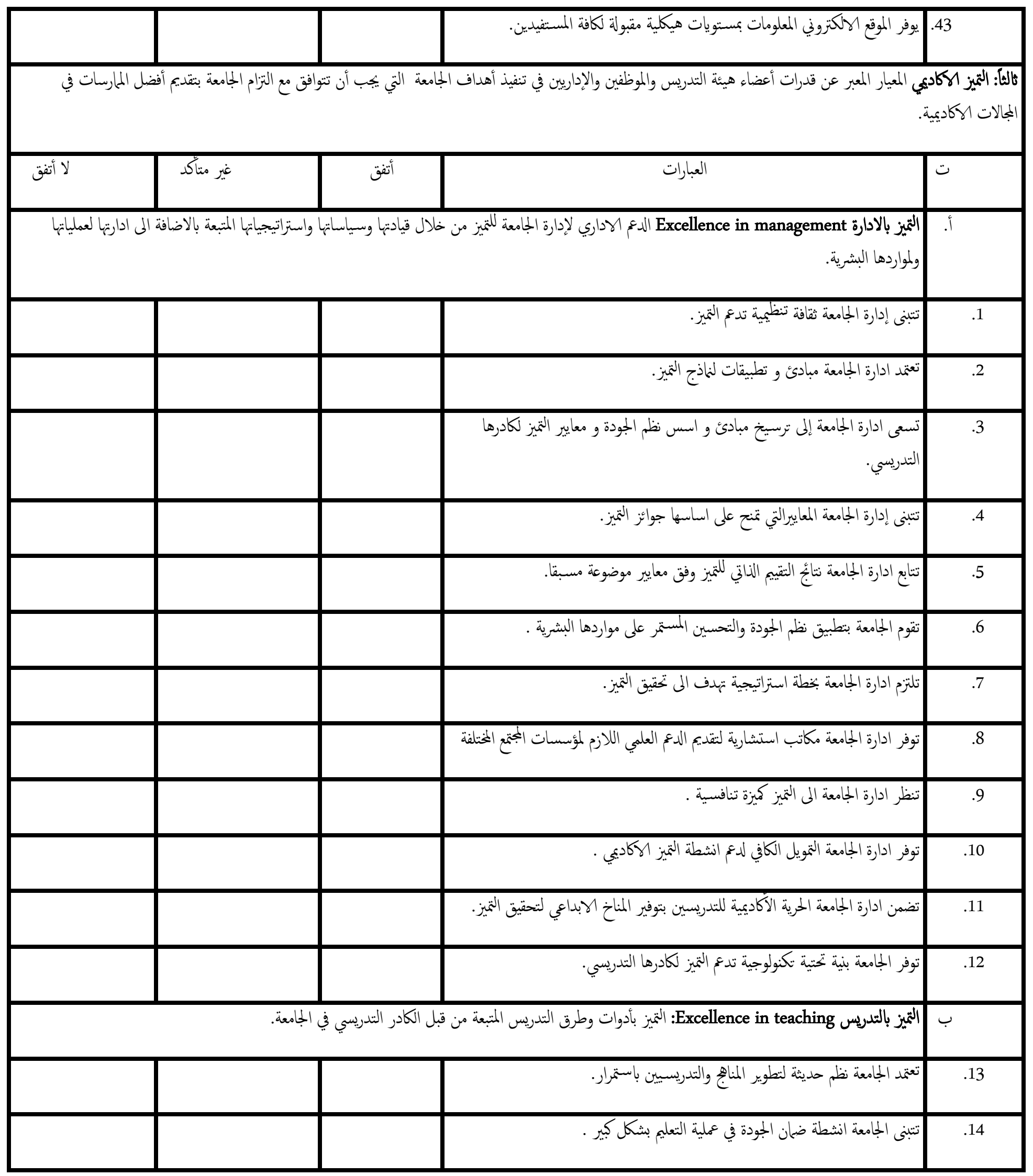




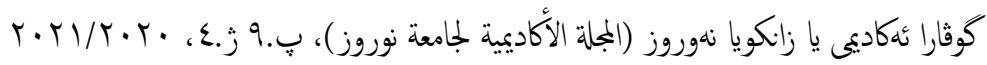

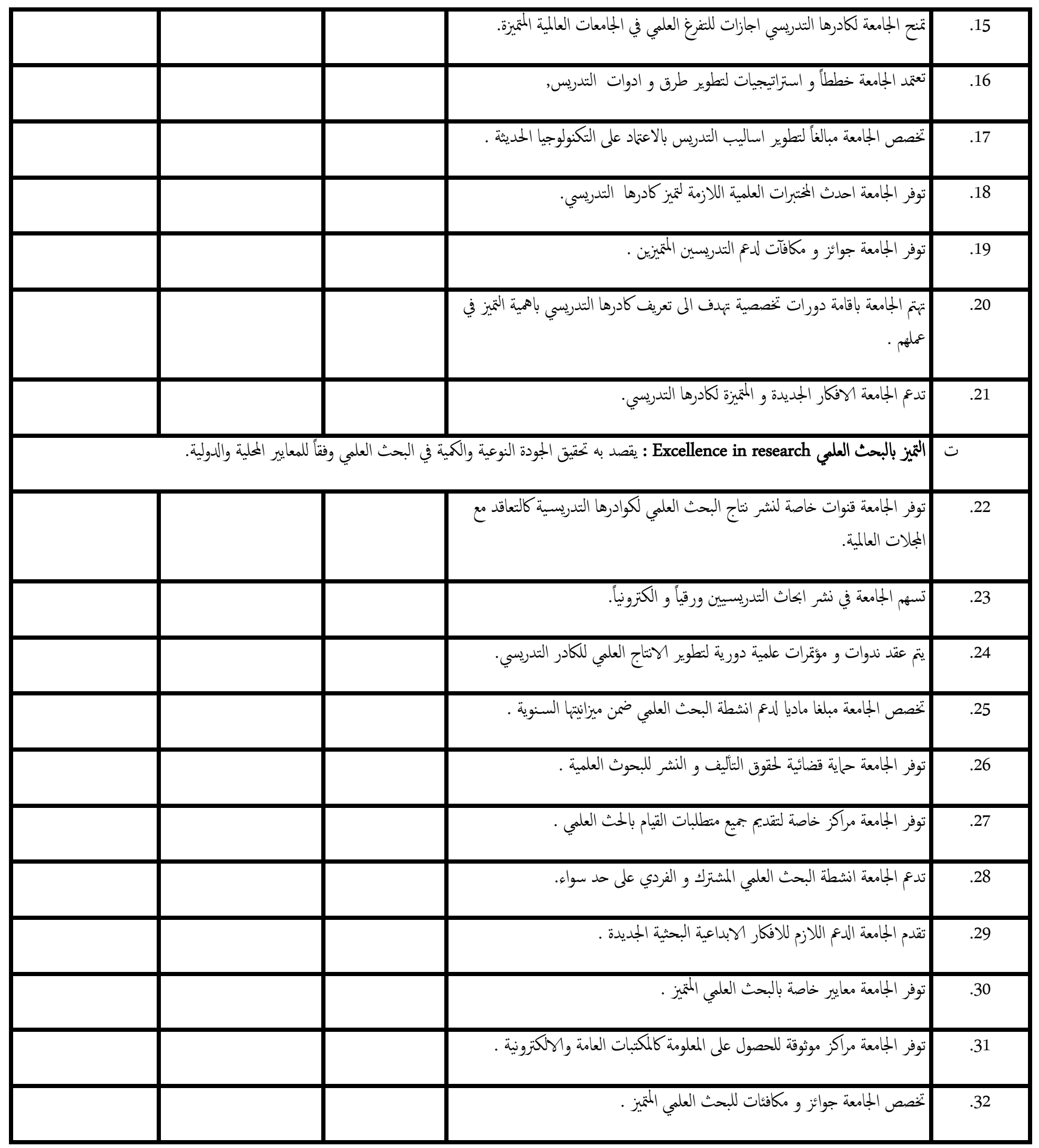




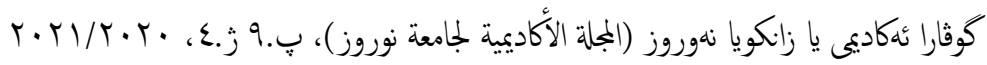

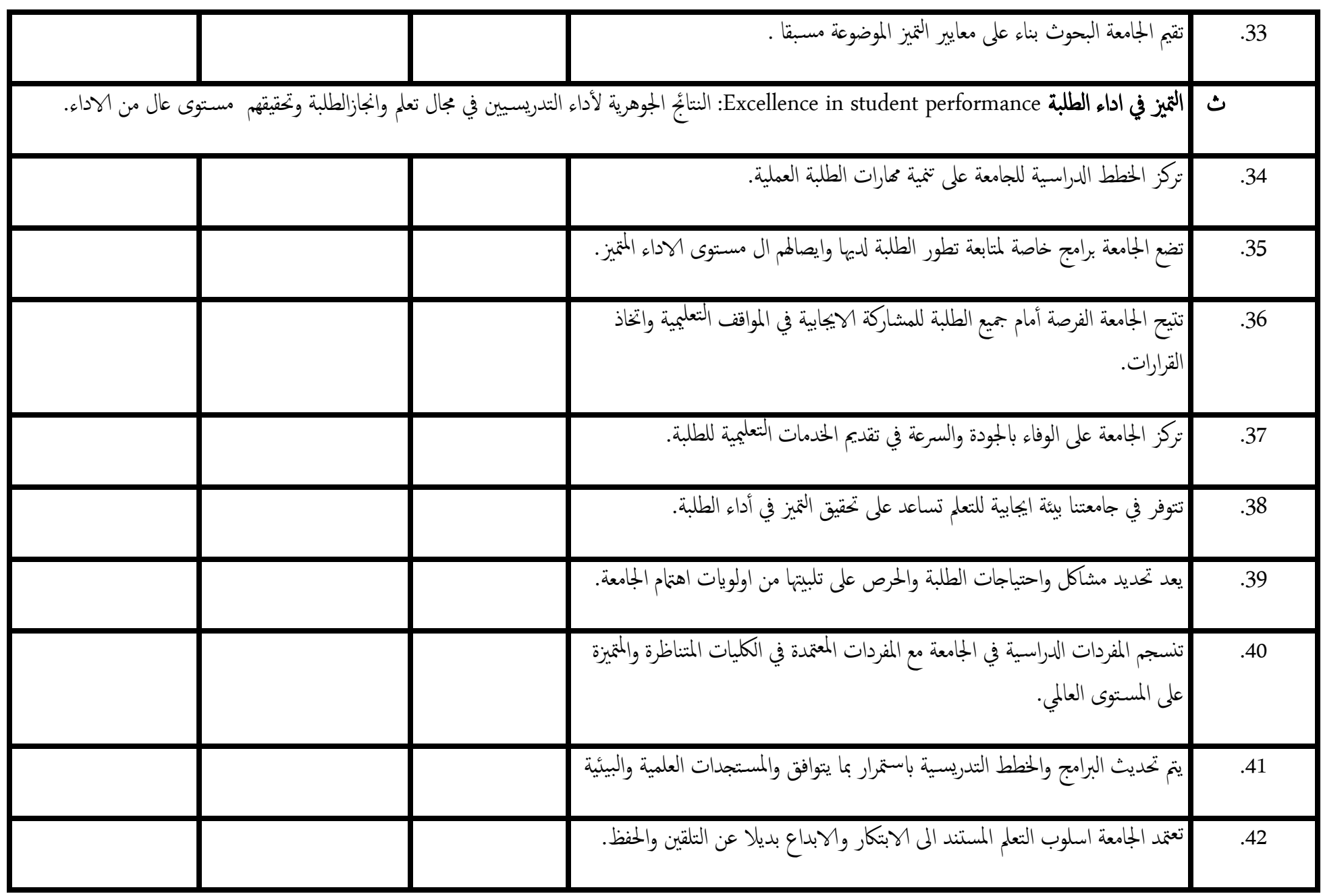

